\title{
Rainfall timing and runoff: The influence of the criterion for rain event separation
}

\author{
Isabel Molina-Sanchis ${ }^{1}$, Roberto Lázaro ${ }^{2 *}$, Eva Arnau-Rosalén ${ }^{3}$, Adolfo Calvo-Cases ${ }^{3}$ \\ ${ }^{1}$ Avenue Juegos del Mediterráneo 1, portal 1, 1ªA. El Toyo, Almería 04131, Spain. E-mail: imolinasanchis@gmail.com \\ ${ }^{2}$ Estación Experimental de Zonas Áridas-CSIC, Carretera de Sacramento s/n, 04120 La Cañada de San Urbano, Almería, Spain. \\ ${ }^{3}$ Department of Geography, University of Valencia, Avenida Blasco Ibañez 28, 46010, Valencia, Spain. Tel.: +34 963864237. \\ Fax:+34 963983054. E-mail: eva.arnau@gmail.com; adolfo.calvo@uv.es \\ *Corresponding author. Tel.: +34 950281045. Fax: +34 950277100. E-mail: lazaro@eeza.csic.es
}

\begin{abstract}
Rain is not uniform in time and space in semiarid areas and its distribution is very important for the runoff process. Hydrological studies usually divide rainfall into events. However, defining rain events is complicated, and rain characteristics vary depending on how the events are delimited. Choosing a minimum inter-event time (MIT) is a commonly used criterion. Our hypothesis is that there will be an optimal MIT that explains the maximum part of the variance of the runoff, with time to runoff used as a surrogate. The objective is to establish a procedure in order to decide upon this optimal MIT. We developed regressions between time to runoff $\left(T_{0}\right)$ and three descriptive variables of rain. Our results show that the optimum MIT is 1 hour, which seems to be the minimum period of time required for water in larger macropores to drain and sufficiently modify the effect of antecedent soil moisture on the runoff generation process. Rain events are classified into three significantly different groups: (1) large and intense rains, (2) light rains on wet soil, and (3) light rains on dry soil. Intense rains produce most of the runoff, but there were significant differences between small events in the runoff generated. Of rain events, $63.75 \%$ are single-tip events, and many could be dew.
\end{abstract}

Keywords: Rain events; Minimum inter-event time (MIT); Runoff; Macrochloa tenacissima (= Stipa tenacissima); Semiarid.

\section{INTRODUCTION}

Rainfall in semi-arid areas is scarce and irregularly distributed over time and space (Bracken et al., 2008; Lázaro et al., 2001; Puigdefábregas et al., 1999). This makes hydrological studies difficult in these areas (Heydarpour, 1989). Runoff is a fundamental process because it leads to water redistribution, and it modulates soil water availability and plant functioning (Huxman et al., 2004; Lázaro, 2004; Sánchez and Puigdefábregas, 1994), especially in semiarid environments (Aguiar and Sala, 1999; Calvo-Cases et al., 2003; Porporato et al., 2002; Puigdefábregas, 2005); and is highly dependent on rainfall.

Understanding the characteristics of rain is essential for both hydrological and climatic studies (Haile et al., 2011). Rain depth, duration and intensity influence the amount of water that plants intercept, as well as evaporation, infiltration, ponding and horizontal flow (Hawke et al., 2006; Struthers et al., 2007). In most cases, studies linking precipitation with hydrological or ecological processes divide rainfall into events. It is not simple to define what a rain event is because the rainfall distribution in time is highly irregular. Although rainfall is a continuous process, the tipping bucket raingauge, which is the most common instrument for measuring rainfall, results in a discretization of the process by the individual tips. This intermittency makes it difficult to define the start and end of events and it directly affects event properties. In the literature, the delimitation of rain events is variable and depends greatly on the subject of study and on the time resolution of the data. According to Brown et al. (1985), rain events are a convenient way to dissect a time series into a set of sections, which is useful for specific applications such as the study of runoff (de Vos and Rientjes, 2008; Zhang et al., 2005), soil erosion (Angel et al., 2005), interception losses (Zeng et al., 2000) and the modelling of rainfall (Abdo et al., 2009; Woolhiser and Osborn, 1985). It seems there is not a 'natural' way to separate events, and we can always relate rainfall and runoff without separating events, by comparing the totals of both series or, if available, the yearly or monthly totals. However, by defining rain events, additional information can be obtained, such as the effects of rain intensity or the effect of antecedent rain. More research on the properties of rain events is necessary and justified by changes in precipitation that may be experienced due to global environmental change (Dunkerley, 2008a).

According to Bonta and Rao (1988), there are several methods for delimitating independent rainfall events, such as choosing a minimum inter-event time dry period (Dunkerley, 2008b), either arbitrarily or based on some reasoned criteria, such as an autocorrelation analysis (Asquith et al., 2005; Wenzel and Voorhees, 1981), choosing a rank correlation coefficient (Grace and Eagleson, 1967) or using the exponential method (Restrepo-Posada and Eagleson, 1982). The works that employ autocorrelation choose a minimum period based on the lag time at which the autocorrelation coefficient falls below a certain threshold. The rank correlation method is similar but it analyses the autocorrelation using the Spearman correlation coefficient which has the advantage of being nonparametric. The exponential method finds the inter-event period that results in exponentially distributed storm arrivals, which is the statistical distribution which would be expected from independent storms following a Poisson process.

To separate events by a defined dry period, a minimum inter-event time (MIT) or minimum dry period between rains is the most used criterion to define rain events. Dunkerley (2008b) showed the great variability of MITs used in the literature. He also showed how many times the criterion for choosing one MIT or another was not specified - a fact that limits the comparison between studies. For example, Bracken et al. (2008) defined rain events as periods without gaps of more than 12 
hours without rain. They chose this MIT because this period is sufficiently long for the soil surface in a semiarid basin to become dry; thus, antecedent soil moisture will not influence the runoff generation. Aryal et al. (2007) adopted an 8-hour MIT in a study to model runoff, after considering that the water stores near the surface were again available after 8 hours. A classic example is that of Wischmeier and Smith (1978), who in their work to predict erosion losses considered events to be separate if there were at least six hours between rainfalls. Changing the MIT alters the number of rainfall events that are created, the characteristics of these events (i.e., the total event depth, mean intensity and duration (Dunkerley, 2008b) and even the relationship that rain has with other ecological processes.

The MIT values usually employed in previous studies range from three minutes to 24 hours (Dunkerley, 2008b). Sometimes, the choice of an MIT is not based on the properties of the rain itself but on other considered processes. For example, Lloyd (1990) adopted a three-hour MIT because this is how long they estimated it would take for the foliage to dry. Bracken et al. (2008) employed an MIT of 12 hours to study the runoff in a southeastern Spanish area, in an attempt to reduce the effect of antecedent moisture. Some studies have added additional criteria, such as specifying a volume (Ziegler et al., 2006) or a minimum rainfall depth (Fornis et al., 2005), or a combination of several criteria (Balme et al., 2006). Other studies (Dunkerley, 2010; Mayor et al., 2011; Usón and Ramos, 2001) have employed an MIT of six hours without specifying the reason for their choice.

Other criteria have also been used to define rain events. Cattan et al. (2006) focussed on the relationship between rainfall and runoff, and defined a rainfall event as a period of more than 15 minutes of continuous precipitation, in such a way that the associated runoff was not interrupted for more than five minutes. Asquith et al. (2005) used autocorrelation analyses for a rainfall series with hourly data. They showed how the average autocorrelations of different sites fell to values close to zero when lags of eight hours are used, and adopted this period as the MIT for their analysis.

Peters and Christensen $(2002$; 2006) used an alternative approach under which a rain event was defined as a continuous uninterrupted sequence of wet periods (time steps); that is, within a rain event, by definition, there are no periods of time without rain. Peters and Christensen (2002) used this definition based on remote sensing data, with a time resolution of one minute. Rain events are considered to be relaxations, similar to what occurs in other processes, such as the energy from earthquakes and avalanches. The power-law distribution of the number and intensity of rain events versus their size is equivalent to the Gutenberg-Richter law for earthquakes and the power-law distribution of avalanche size (Peters et al., 2002). This approach, although theoretically well founded, does not serve our purpose because it results in many small events that are often spaced very close together; thus, one event is highly dependent on the preceding one and may be unrelated to the runoff. This method is called adjacent wet intervals (AWI) and was studied by Ignaccolo and de Michele (2010), who compared the MIT and AWI approaches, and provided theoretical arguments to show that both were equivalent in some cases and subject to some arbitrariness. They proposed a point-based definition for rain events, relying on properties of the time intervals between drops. This is a dynamic and very complex definition based on data from a disdrometer.

Our hypothesis is that, for many of the rainfall-dependent processes, specifically for runoff, there will be an optimal MIT that allows us to explain the maximum part of the variance of the runoff process, specifically of the time to runoff (used here as a surrogated variable). Since there is no widely accepted criterion in the literature to identify events (Bonta and Rao, 1988; Dunkerley, 2008b), and to avoid arbitrariness in selecting the MIT, our purpose here is to study the temporal distribution of precipitation and analyse how the rain event definition affects the relationship between precipitation and runoff, while considering both processes at detailed scales (plot spatial scale and min-hr timescale). The specific objectives are to establish a criterion for deciding the most appropriate MIT in order to optimise the explanation of the runoff at plot scale, as well as to assess the effect of the choice of MIT on runoff.

\section{METHODS}

The study was conducted in the experimental area of Balsa Blanca (BB), located in Cabo de Gata-Nijar Natural Park (Almería), in the southeast of Spain. The climate is semi-arid Mediterranean with an annual average temperature of $18-19^{\circ} \mathrm{C}$ and about $240 \mathrm{~mm}$ total rainfall per year. The rainfall shows strong inter- and intra-annual variations, but there are 9-12 months in which the rainfall is not enough to compensate for potential evapotranspiration. The relative humidity is high due to proximity to the sea, and dew is frequent. The topography is smooth, with slopes of $3-10^{\circ}$. The soils are classified as Mollic-Lithic Leptosols (Calcaric); they are shallow and stony, and contain $16.1 \%$ clay, $22.8 \%$ silt and $61.1 \%$ sand (Rey et al., 2011). There is a petrocalcic horizon that has frequent outcrops. The vegetation is dominated by Macrochloa tenacissima, but includes frequent shrubs, such as Phlomis purpurea and Ulex parviflorus, as well as scattered late-successional bushes (Chamaerops humilis L., Olea europaea L. var. sylvestris Brot., Pistacia lentiscus L., Rhamnus lycioides L. and Quercus coccifera L.) (Mora and Lázaro, 2013).

Precipitation was registered with a Davis rain gauge, model 7852 , double tipping bucket, connected to an Onset HOBO Event Data Logger H07-002-04, which was located $1.5 \mathrm{~m}$ from the ground and has a resolution of $0.2386 \mathrm{~mm}$ per tip. Runoff was registered in 16 open plots, each one with a double-tipping bucket system similar to that of the rain gauges, which store data on fixed volumes of runoff at varying times in a HOBO Pendant Event Data Logger UA-003-64. All of the plots are in the same hillslope but with different surface properties. There are two main groups of plots: those dominated by vegetation and by bare soil. Within the first group, we distinguished two dominant species and two vegetation patch sizes; within the second group, stonier soils were distinguished from less stony soils. Because of this, the plots have different widths (i.e., the collector channels have different lengths). The tipping buckets of the plots have six sizes, with the water volume capacity in each half being $0.05,0.075,0.15,0.25,0.3$ and $0.35 \mathrm{~L}$, respectively. These sizes were distributed among the plots according to two criteria: the length of the collector and the features of the vegetation. Although we could not anticipate the volume of runoff to be collected, the size of the tipping buckets was sufficient to record runoff with a resolution in $\mathrm{mm}$ greater than that of the rain gauge $(0.224 \mathrm{~mm})$ even for plots with high runoff coefficients, avoiding to increase the natural delay between rainfall and runoff, and keeping so the accuracy of $T_{0}$. The available data set of rain and runoff came from April 2009 to November 2012. In 2010 and 2011, total annual rainfalls of 372 and $300 \mathrm{~mm}$ were reached, respectively.

The rainfall time distribution was examined by plotting the daily totals for each year, as well as with an autocorrelation analysis of cumulative rainfall data every five minutes of the 
complete rainfall series (including zeros), with up to 1000 lags (equivalent to 3.47 days) using SPSS v19 for Windows (SPSS Inc., Chicago, IL, USA). We also studied the frequency distribution of the lengths of the periods between tips, as it provides information on the rainfall timing and intensity at any temporal scale.

We have grouped the rainfall data according to six different MITs, ranging from 24 hours to 30 minutes. To describe the events generated in each case we calculated the following parameters: total rain depth, duration, mean intensity, maximum intensities at 60 and 5 minutes $\left(I_{60 \max }\right.$ and $\left.I_{5 \max }\right)$, number of single-tip events, total volume collected in single-tip events and mean duration of dry periods between rainfalls, known as interevent time (IET) (Haile et al., 2011).

To choose an MIT that optimised the relationship between rainfall and runoff, we created a database of rainfall and runoff for each MIT considered. We have associated the runoff tips that occur between the first tip of rain and a maximum of 30 minutes after the last tip within each rain event. For each event, different rainfall parameters were calculated: the IET, the amount of precipitation for the runoff to start $\left(P_{0}\right)$, the mean intensity of the rain fallen down from rain starts until $P_{0}$ is reached $\left(I_{0}\right)$ and a parameter representative of runoff and time to runoff $\left(T_{0}\right)$. We used mean rainfall intensity rather than maximum intensity because the intensities were quite low in our events in general. The maximum intensities were not always relevant for runoff, because most of them had short or very short durations. The mean intensity was much more closely related with $T_{0}$ than the maximum intensity (for example, $\mathrm{R}^{2}$ for the mean intensity was 0.719 and 0.807 for plots 2 and 6 , respectively, whereas for the maximum intensity, it was 0.004 and 0.102 for the same plots). Runoff is a sporadic process in semiarid environments; many rainfall events produce zero runoff volume. Because of this, the statistical distributions of rainfall and runoff are not normal, which hinders the study of the direct relationship between rainfall and runoff. However, the surrogate variables mentioned above fulfil the parametric assumptions. The study of IET allows the indirect consideration of antecedent soil moisture, which is an important factor for runoff, and at the same time, helps to avoid selecting a very large MIT in order to ensure that the antecedent conditions are not important, which is advisable because, when using very large MITs, the internal complexity of the rainfall events tends to increase, while the number of events and the time resolution decrease. For calculating the IET, we have not taken rain events into account with volumes $\leq 0.71 \mathrm{~mm}$ (three tips) because they have a negligible effect on the antecedent soil moisture and, therefore, on the next event. Firstly, the relationship between the IET and $T_{0}$ was analysed to see how it varied according to antecedent soil moisture and how this relationship varies for different MITs. Secondly, the mean intensity of $P_{0}\left(I_{0}\right)$ - another factor that strongly influences the runoff - was included in the regression analysis. Finally, the rainfall to runoff relationship was also added, and a multiple regression was performed for each MIT between $T_{0}$ and the three descriptive variables of rain $\left(P_{0}, I_{0}\right.$ and IET). We assumed that the most appropriate MIT would be the model that explained the largest variance of $T_{0}$.

Once the optimal MIT was determined, the rain events for this MIT were classified. We used K-means clustering to perform an agglomerative classification and maximise the initial distances between clusters, using the following characteristics of rainfall as variables: total event depth (Volumm); duration (Duraho); three intensities $\left(I_{60 \max }, I_{30 \max }\right.$ and $\left.I_{10 \max }\right)$; and cumulative rainfall one, five and ten days before the event (LluO1d,
Llu05d and Llu10d). The distinctive characteristics of each group resulting from the classification have also been described. The differences in runoff volume among the rainfall groups were examined using Kruskal-Wallis tests. Regression and cluster analyses were performed with StatSoft, Inc. (2005) STATISTICA software (data analysis software system), version 7.1 (www.statsoft.com). To assess the overall effect of selecting one MIT or another on runoff, the average runoff in $\mathrm{mm}$ for every MIT was calculated, for a representative series of six plots.

\section{RESULTS \\ Temporal rainfall distribution}

The rains are irregularly distributed throughout the year, but they are more frequent in the first and last months of the year (Figure 1), resulting in very dry summers. The autocorrelation coefficient of the rainfall time series (Figure 2) decreases exponentially as the delay (number of lags) increases. The first time the coefficient fell below the threshold of significance was at 23 hours (277 lags), which could indicate that the rainfalls of consecutive days are different.

The different lengths of time periods between consecutive tips of rain have been grouped into 40 classes, which range, from values close to zero up to 38 days (Figure 3). The most abundant rainless periods are of less than 24 hours, and $90 \%$ are less than 1 hour; only $6 \%$ of the gap sizes were greater than 24 hours.

Table 1 shows how the characteristics of rain events vary depending on the MIT elected to define events. Using a 24-hour MIT reduced the number of rain events, in relation to a 30 minute MIT, to less than one-third. The mean rain event depth increased by three times, and the event duration decreased exponentially. For the maximum intensities, the changes were not large, but were slightly more marked in the case of $I_{5 \max }$.

However, contrarily, the mean intensities decreased when the MIT increased. Events with a single tip represented $40.96 \%$ of all events for the 24-hour MIT but only $1.98 \%$ of the total rainfall amount $(\mathrm{mm})$, whereas the single-tip events reached $66.45 \%$ of the events and $12.33 \%$ of the total $\mathrm{mm}$ for the case of the 30-minute MIT. The largest IET was 38 days (between 03/05/2012 and 10/06/2012) - between two single-tip events. If we ignore the events with only one and two tips, the largest IET was 91.7 days (between 02/06/2011 and 01/09/2011) for the 24hour MIT and 128.55 days (between 10/05/2009 and 15/09/09) for the 30-minute MIT.

For all of the MITs studied, the largest event, in terms of the recorded rain depth, occurred in late September 2009. The depth accumulated at this time varied from $92 \mathrm{~mm}$ for the 24hour MIT to $55.8 \mathrm{~mm}$ for the 30-minute MIT. The longer rain durations occurred between December and February for any MIT, and ranged from 7.5 days for the 24-hour MIT to 11 hours for the 30-minute MIT.

\section{Identifying the best MIT to define rainfall events, considering the associated runoff}

The relationship between IET and $T_{0}$ was studied for the different runoff plots (Figure 4) using three series of regressions, the first one being a simple linear regression. For this simple expression of $T_{0}$ as a function of IET, the fitting lines are shown in Fig. 4 to illustrate the positive relationship between $T_{0}$ and IET. Due to the effect of antecedent conditions, the more separated the rainfall events are, the more time is required for runoff initiation. $T_{0}$ is small when it rains over wet soil. 

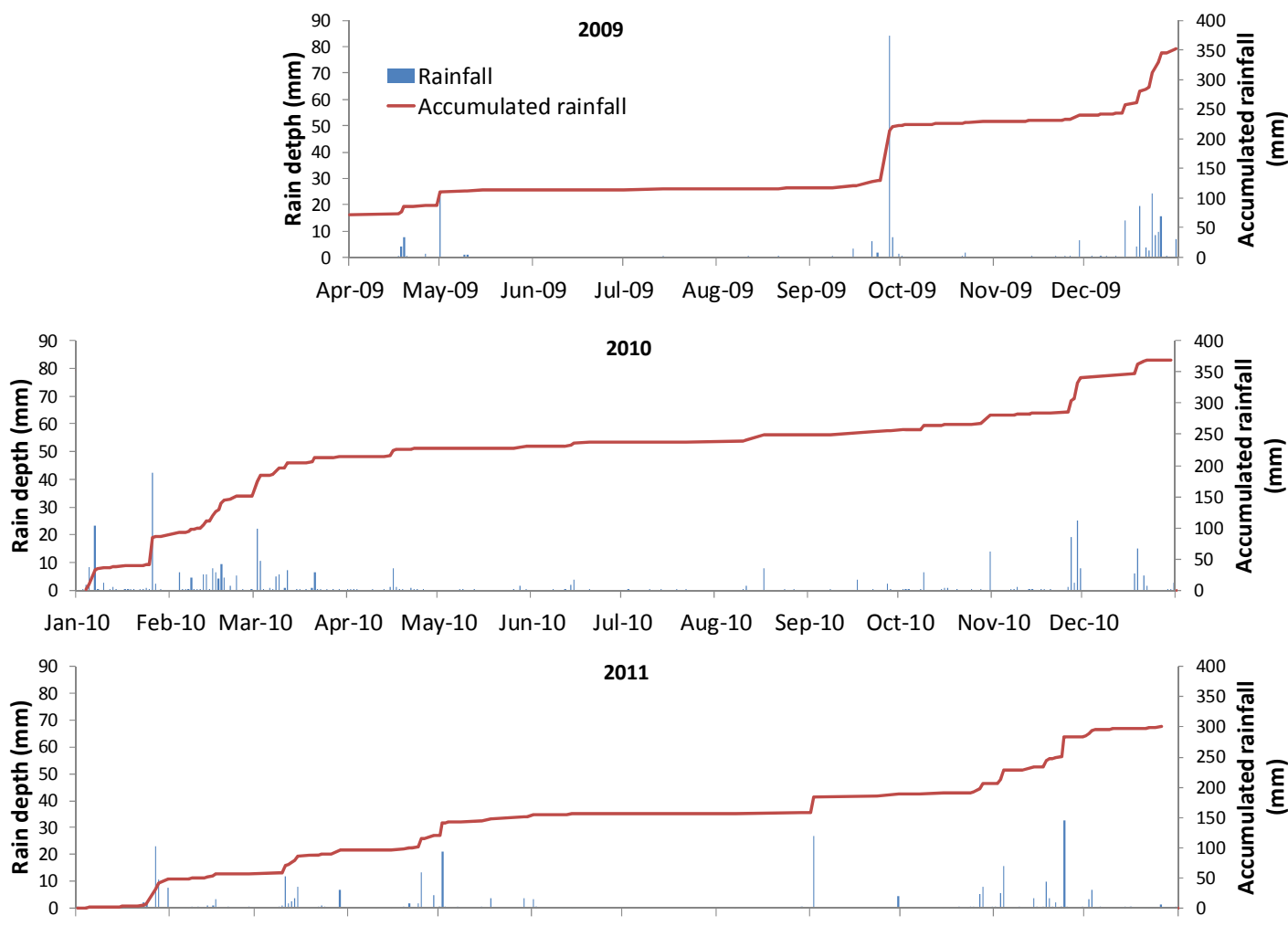

Jan-11 Feb-11 Mar-11 Apr-11 May-11 Jun-11 Jul-11 Aug-11 Sep-11 Oct-11 Nov-11 Dec-11

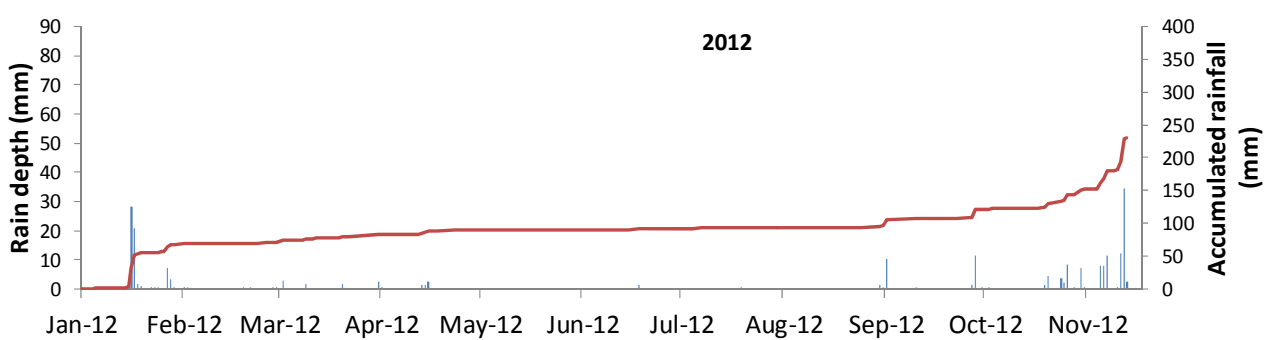

Fig. 1. Daily rainfall distribution by year. In the main axis, the daily rainfall depth $(\mathrm{mm})$ is shown. In the secondary axis, the accumulated rainfall $(\mathrm{mm})$ for each year is shown.

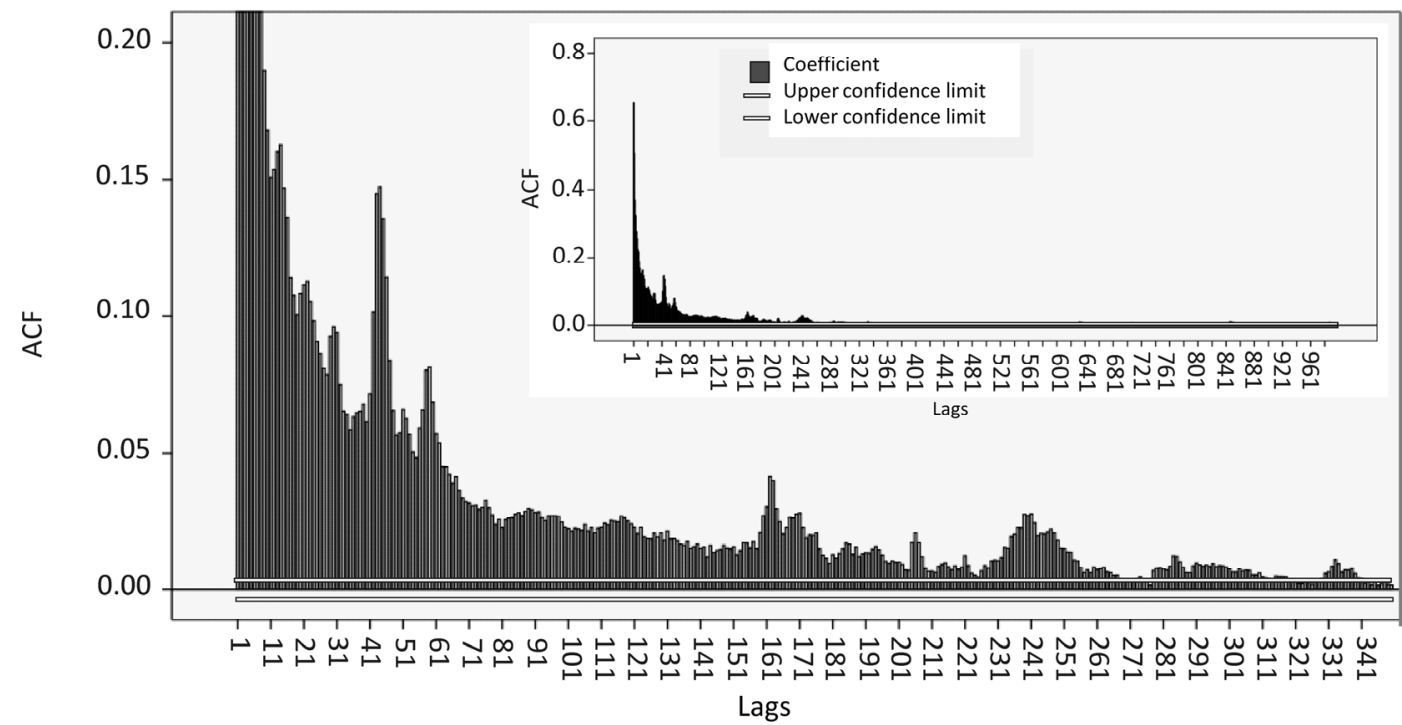

Fig. 2. Autocorrelation coefficient vs. number of lags. Each lag is equivalent to moving the series five minutes ahead, up to 999 delays (3.47 days). Coefficients higher than the white line are significant at $\mathrm{p}<0.05$. 

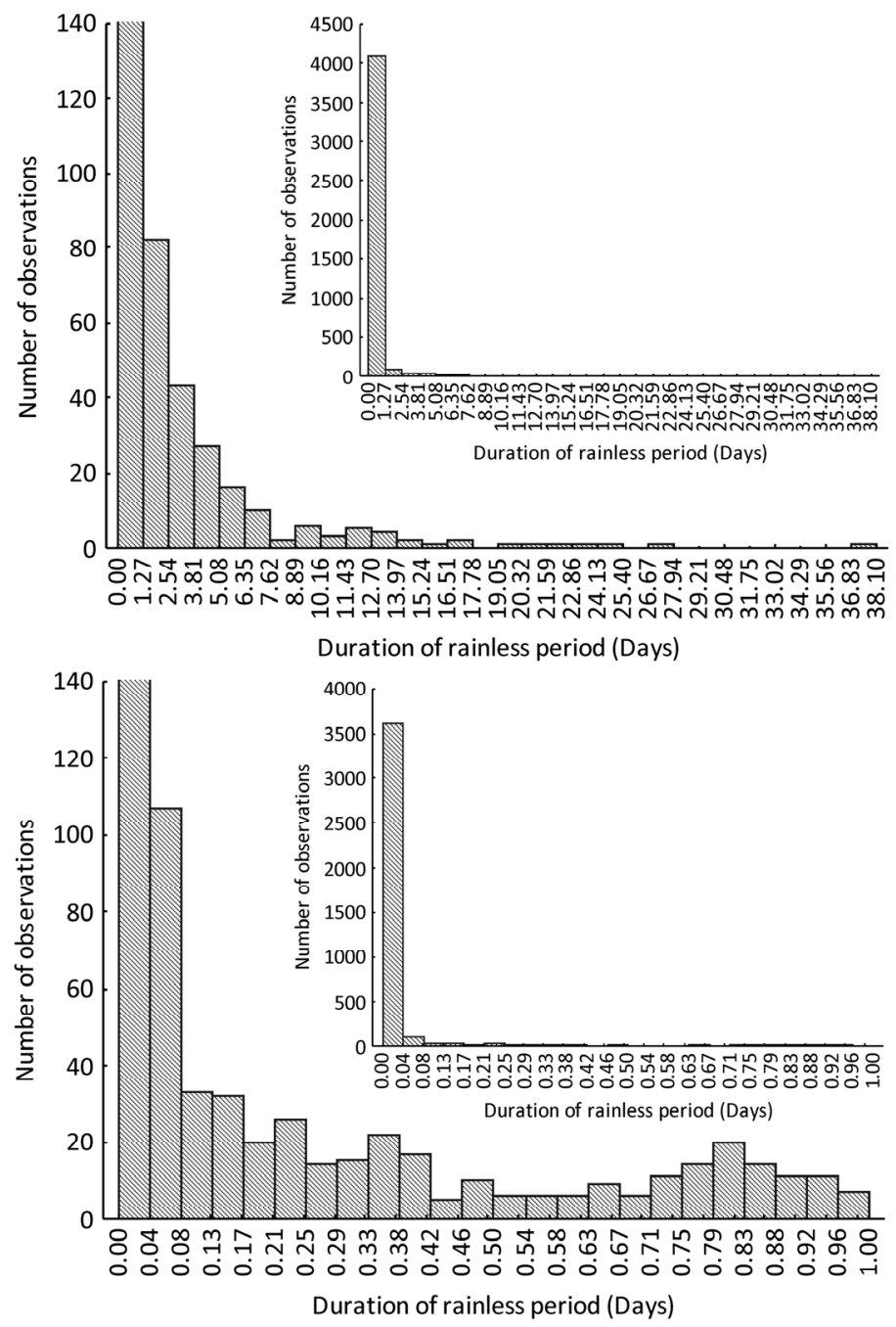

Fig. 3. Frequency histograms of period size between consecutive tips of rain. The graph on the top shows the histogram for the entire range, while the graph at the bottom shows it for gaps shorter than 24 hours.

Table 1. Characteristics of rain events and periods between rainfalls, depending on the different MITs, ranging from 30 minutes to 24 hours, used to define events.

\begin{tabular}{|c|c|c|c|c|c|c|c|c|c|}
\hline MIT & $\begin{array}{c}\text { No. } \\
\text { events }\end{array}$ & $\begin{array}{l}\text { Mean } \\
\text { event } \\
\text { depth } \\
(\mathrm{mm})\end{array}$ & $\begin{array}{c}\text { Mean } \\
\text { event } \\
\text { duration } \\
\text { (h) } \\
\end{array}$ & $\begin{array}{c}\text { Mean } \\
\mathbf{I}_{5 \mathrm{max}} \\
\left(\mathrm{mmh}^{-1}\right)\end{array}$ & $\begin{array}{c}\text { Mean } \\
\text { I }_{60 \mathrm{max}} \\
\left(\mathrm{mmh}^{-1}\right)\end{array}$ & $\begin{array}{l}\text { Mean event rain } \\
\text { rate }\left(\mathbf{m m h}^{-\mathbf{1}}\right) \\
\text { (single-tip events } \\
\text { not included) }\end{array}$ & $\begin{array}{l}\text { No. single- } \\
\text { tip events }\end{array}$ & $\begin{array}{l}\text { Single-tip } \\
\text { event rain } \\
\text { depth } \\
\text { (mm) }\end{array}$ & $\begin{array}{c}\text { Mean IET } \\
\text { duration } \\
\text { (days) }\end{array}$ \\
\hline $24 \mathrm{~h}$ & 271 & 4.37 & 15.90 & 7.87 & 1.74 & 1.70 & 111 & 26.48 & 4.17 \\
\hline $12 \mathrm{~h}$ & 398 & 2.97 & 4.85 & 6.55 & 1.33 & 1.93 & 217 & 51.78 & 3.09 \\
\hline $6 \mathrm{~h}$ & 493 & 2.40 & 2.23 & 6.05 & 1.19 & 2.58 & 320 & 76.35 & 2.56 \\
\hline $3 \mathrm{~h}$ & 581 & 2.04 & 1.22 & 5.80 & 1.15 & 3.12 & 389 & 92.82 & 2.20 \\
\hline $1 \mathrm{~h}$ & 745 & 1.59 & 0.59 & 5.50 & 1.08 & 3.55 & 475 & 113.34 & 1.73 \\
\hline $30 \mathrm{~min}$ & 921 & 1.29 & 0.34 & 5.26 & 1.08 & 4.51 & 612 & 146.02 & 1.41 \\
\hline
\end{tabular}

Additionally, the data dispersion was small, and the differences among the plots in the slopes of the fitting lines were moderate, showing the robustness of the relationship between $T_{0}$ and IET.

The other series of regressions, adding $I_{0}$ and then $I_{0}$ plus $P_{0}$ as independent variables, showed that while $P_{0}$ had positive relationship with $T_{0}, I_{0}$ had a negative relationship. If runoff requires more rain to begin, then more time is usually required for the start of runoff, showing that natural intensities are often not very variable. Nevertheless, the larger the intensity, the shorter the $T_{0}$, particularly when the values of $P_{0}$ are not very different. In general, and for the three types of regressions, the lower the MIT, the larger the variance of $T_{0}$ accounted for. But there were two exceptions (Table 2): (i) The 30-minute MIT accounted for lower variance than the 1-hour MIT; and (ii) the 3-hour MIT showed unexpected lower values and often did not follow the increase in determination coefficient with decreasing MIT, except in the case of the regression with three independent variables.

The coefficients of determination $\left(\mathrm{R}^{2}\right)$ for each type of regression model and each MIT are shown in Table 2, for a selection of six plots that are representative of the main surface types. The regression types becoming progressively more complex accounted for progressively larger amounts of the variance of $T_{0}$, despite the high diversity of rainfall types involved. 


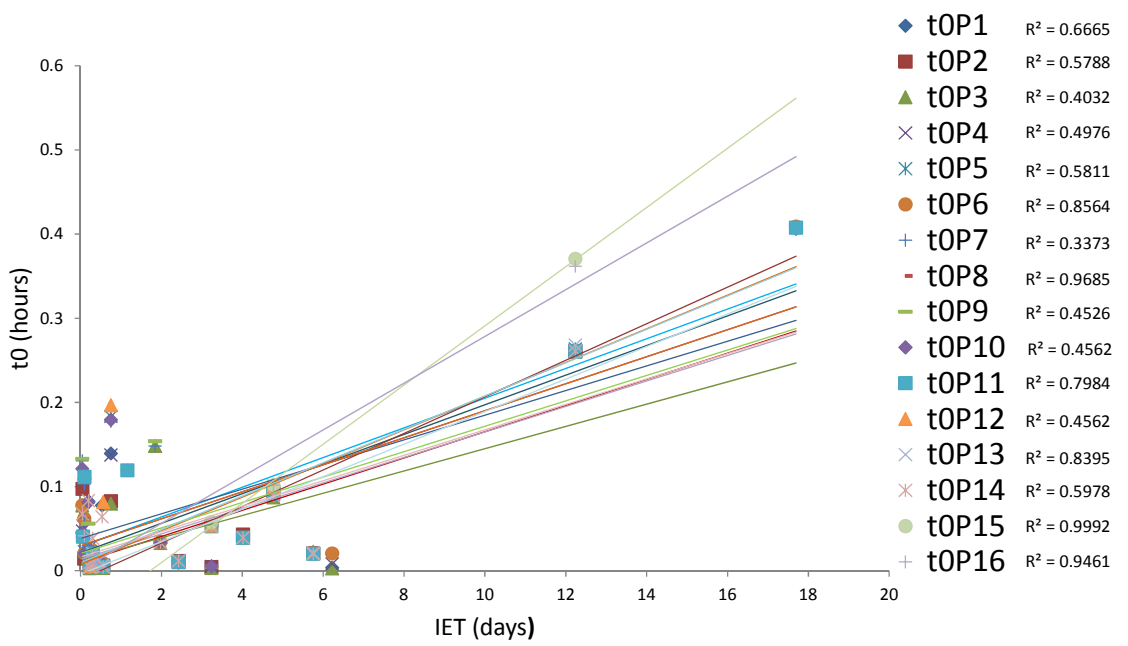

Fig. 4. Relationship between time to runoff $\left(t_{0}\right)$ and the rainless period between consecutive events (IET), for events that were generated with 1-hour MIT and for each of the 16 runoff plots $(\mathrm{P})$. On the right is the coefficient of determination $\left(\mathrm{R}^{2}\right)$ for each plot.

Table 2. Coefficients of determination $\left(\mathrm{R}^{2}\right)$ for all of the regressions, for a representative selection of plots $(\mathrm{P})$, according to the chosen MIT (30 min or $1,3,6,12$ or $24 \mathrm{~h})$. On the left side, the three regressions studied $\left(t_{0} \sim I E T, t_{0} \sim I E T+I_{0}\right.$ and $\left.t_{0} \sim I E T+P_{0}+I_{0}\right)$ and the $\mathrm{R}^{2}$ corresponding to the statistically significant analysis are mentioned and in bold.

\begin{tabular}{|c|c|c|c|c|c|c|}
\hline & Plot2 & Plot3 & Plot6 & Plot7 & Plot9 & Plot13 \\
\hline \multicolumn{7}{|l|}{$\mathrm{t}_{0} \sim$ IET } \\
\hline $24 \mathrm{~h}$ & 0.03 & 0.11 & 0.03 & 0.00 & 0.09 & 0.40 \\
\hline $12 \mathrm{~h}$ & 0.24 & 0.00 & 0.26 & 0.05 & 0.01 & 0.08 \\
\hline $6 \mathrm{~h}$ & 0.35 & 0.07 & 0.25 & 0.28 & 0.00 & 0.00 \\
\hline $3 \mathrm{~h}$ & 0.05 & 0.16 & 0.03 & 0.03 & 0.10 & 0.12 \\
\hline $1 \mathrm{~h}$ & 0.57 & $\begin{array}{l}0.40 \\
\end{array}$ & $\begin{array}{ll}0.85 \\
\end{array}$ & $\begin{array}{l}0.33 \\
\end{array}$ & 0.45 & 0.83 \\
\hline $30 \mathrm{~min}$ & 0.00 & 0.00 & 0.02 & 0.00 & 0.00 & 0.00 \\
\hline \multicolumn{7}{|c|}{$t_{0} \sim I E T+I_{0}$} \\
\hline $24 \mathrm{~h}$ & 0.32 & 0.29 & 0.38 & 0.35 & 0.31 & 0.42 \\
\hline $12 \mathrm{~h}$ & 0.50 & 0.19 & 0.49 & 0.48 & 0.36 & 0.52 \\
\hline $6 \mathrm{~h}$ & 0.49 & 0.27 & 0.36 & 0.40 & 0.39 & 0.49 \\
\hline $3 \mathrm{~h}$ & 0.27 & 0.26 & 0.29 & 0.25 & 0.32 & 0.37 \\
\hline $1 \mathrm{~h}$ & 0.68 & 0.67 & 0.86 & 0.57 & 0.61 & 0.84 \\
\hline $30 \mathrm{~min}$ & $\begin{array}{l}0.48 \\
\end{array}$ & $\begin{array}{l}0.38 \\
\end{array}$ & 0.47 & 0.33 & $\begin{array}{l}0.39 \\
\end{array}$ & 0.41 \\
\hline \multicolumn{7}{|c|}{$\mathbf{t}_{0} \sim \mathbf{I E T}+\mathbf{P}_{0}+\mathbf{I}_{0}$} \\
\hline $24 \mathrm{~h}$ & 0.53 & 0.49 & 0.47 & 0.60 & 0.60 & 0.80 \\
\hline $12 \mathrm{~h}$ & 0.67 & 0.34 & 0.59 & 0.53 & 0.38 & 0.55 \\
\hline $6 \mathrm{~h}$ & 0.64 & 0.77 & 0.61 & 0.54 & 0.70 & 0.80 \\
\hline $3 \mathrm{~h}$ & 0.72 & 0.80 & 0.72 & 0.53 & 0.66 & 0.80 \\
\hline $1 \mathrm{~h}$ & 0.81 & 0.82 & $\begin{array}{ll}0.88 \\
\end{array}$ & 0.88 & 0.92 & 0.91 \\
\hline $30 \mathrm{~min}$ & 0.74 & 0.74 & 0.56 & 0.85 & $\begin{array}{l}0.88 \\
\end{array}$ & 0.89 \\
\hline
\end{tabular}

In all of the analyses (in each regression type), the MIT of 1 hour reached the highest $\mathrm{R}^{2}$, which was over 0.8 in all the plots (Table 2), despite the very different surface types and vegetation covers, and the results of all of the regression types were statistically significant in every plot for this MIT.

\section{Characteristics of the rain events for a one-hour MIT}

After choosing the one-hour MIT as the most appropriate to define rainfall events, we found that there was independence between the intensity $\left(I_{5 \max }\right)$ and duration of rainfall. However, there was some dependence between the intensity and rain depth, with the more intense rains usually having the larger $I_{5 \max }$ (Figure 5).

A total of 745 events were recorded. Of this total, $63.75 \%$ were events with one single-tip, which accounted for $9.57 \%$ of the total $\mathrm{mm}$ recorded. Of these tips, $66 \%$ occurred at night (between 23:00 and 8:00). The longest rainfall occurred in late November and lasted 17 hours. The maximum rain depth was $77.06 \mathrm{~mm}$, during an event lasted 5.7 hours. The most intense event with rainfall depth larger than $3 \mathrm{~mm}$ occurred on November 19th, 2011, with a mean I of $20.28 \mathrm{~mm} \mathrm{~h}^{-1}$, a total depth of $3.34 \mathrm{~mm}$ and a duration of approximately 10 minutes. The longer period of time between rainfall events, if we remove events with less than or equal to two tips, was the same as the 30-minute MIT. If we do not consider the single-tip events, the mean duration between rainfall events increased from 1.73 days (Table 1) to 15.13 days, and the mean rain depth increases to $6 \mathrm{~mm}$.

\section{Classification of rain event types}

We classified rain events (separated by a one-hour MIT) based exclusively on rain characteristics. If we create two groups, the number of events in each one would be very unequal. One group would contain only the five big events, and the other group would contain the rest. Figure 6 a shows the results of cluster analyses to generate three groups. Two clusters have small volumes and low intensities but differ in the antecedent soil moisture. The third cluster, with the five events mentioned 

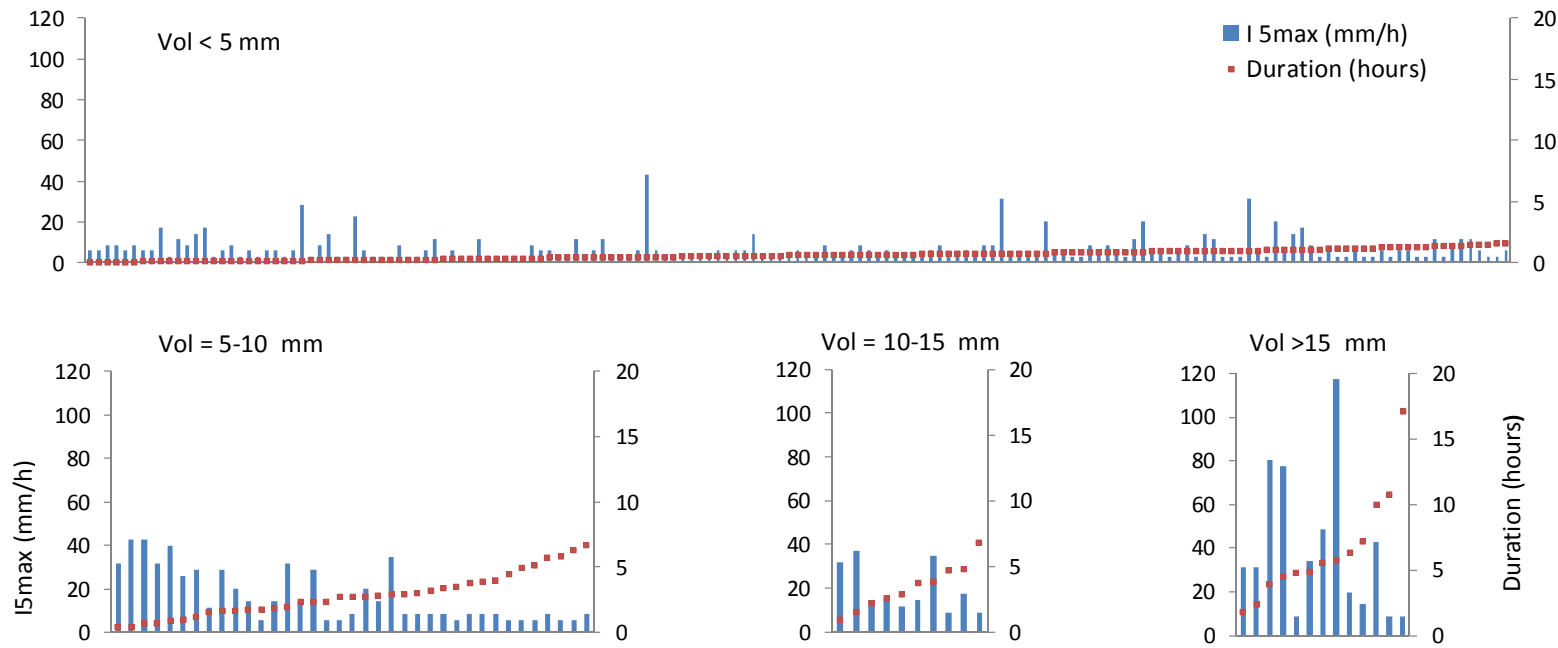

Fig. 5. Summary of the event characteristics (volume, duration and intensity $I_{5 \max }$ ) generated with 1-hour MIT. Single-tip events are not shown. Each graph is for different ranges of rain depths. The events are ordered from left to right, from low to high duration of the event.

a)

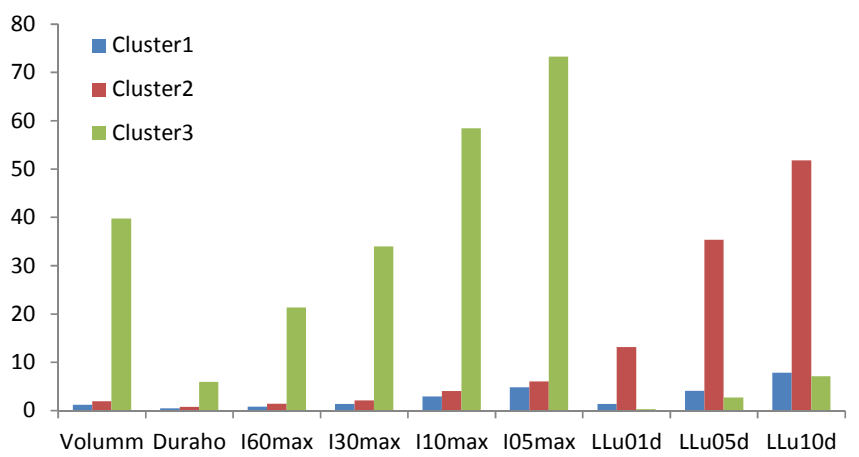

b)

\begin{tabular}{lcccccc} 
Variable & Between SS & df & Within SS & df & F & signif. P \\
\hline Volumm & 7400.1 & 2 & 7979.28 & 742 & 344.07 & 0.000000 \\
Duraho & 155.3 & 2 & 1258.84 & 742 & 45.76 & 0.000000 \\
I60max & 2114.6 & 2 & 2489.27 & 742 & 315.17 & 0.000000 \\
I30max & 5299.9 & 2 & 5698.57 & 742 & 345.04 & 0.000000 \\
I10max & 15296.2 & 2 & 16280.8 & 742 & 348.56 & 0.000000 \\
I5max & 23320.7 & 2 & 28909.62 & 742 & 299.28 & 0.000000 \\
Llu01d & 16020.5 & 2 & 47147.77 & 742 & 126.06 & 0.000000 \\
Llu05d & 112542.8 & 2 & 76826.63 & 742 & 543.48 & 0.000000 \\
Llu10d & 221941.7 & 2 & 97250.39 & 742 & 846.68 & 0.000000
\end{tabular}

Fig. 6. a) Characteristics of the three types of rain events established. On the X-axis, each of the rainfall characteristics included in the analysis are described: total event depth (Volumm); duration (Duraho); different maximum I values $\left(I_{60 \max }\right.$, and $\left.I_{10 \max } I_{30 \max }\right)$; and cumulative rainfall 1,5 and 10 days before the event (Llu01d, Llu05d and Llu10d). b) Results of the analysis of variance.

above, have intense events with large volumes. We included three variables (Llu01d, Llu05d and Llu10d) in the classification because the cumulative rainfall days before the target event can affect runoff generation. We decided against making larger number of groups because some would contain only one or two rain events and would not be distinct in their effect on runoff. When making three groups, the clusters showed significant differences in all of the variables (Figure 6b).

Figure 7 shows the cumulative rainfall graphs for nine typical events: three rain events for each cluster generated. Singletip rains accounted for $68 \%$ of the events in cluster one and
$47.8 \%$ in cluster two. In cluster three, the events had different profiles and may be complex events, including several peaks of intensity.

Runoff (in mm, supposing a length of $0.5 \mathrm{~m}$ for each plot, upstream of the channel) varied significantly between the rain groups in every plot (Table 3 ). As an example, the mean runoff values were $0.243 \mathrm{~mm}$ and $0.405 \mathrm{~mm}$ in plots 1 (high vegetation cover) and 2 (very low vegetation cover), respectively, for the rainfalls of cluster $1 ; 0.062 \mathrm{~mm}$ and $0.097 \mathrm{~mm}$ for cluster 2 , and $2.114 \mathrm{~mm}$ and $12.605 \mathrm{~mm}$ for cluster 3 .

\section{Assessment of the effect of MIT on runoff}

The effect of increasing MIT was to increase the average runoff expressed in mm (although the total runoff of the studied period remains invariant). If the events without runoff are not considered, then the effect of the MIT choice is moderate: the ratio between the runoff for a 24-hour MIT and a 30-minute MIT ranged from 1.11 to 1.80 , depending on the plot features.

However, the number of events producing runoff obviously varies with the MIT and therefore it is more correct to compare MITs using all the events. When all of the events are considered then the runoff varies considerably and the ratio of $24 \mathrm{~h}$ MIT/30min MIT is 3.24, independent of the plot features (the ratios of the $12 \mathrm{~h}, 6 \mathrm{~h}, 3 \mathrm{~h}$ and $1 \mathrm{~h}$ MITs with regard to $30 \mathrm{~min}$ MIT were 2.33, 1.96, 1.64 and 1.26, respectively, also the same for all the plots).

\section{DISCUSSION AND CONCLUSIONS}

We decided to employ the MIT criterion because it is widely used in the literature; it is simple and easy to apply. It allows rain to be recorded with rain gauges; additionally, it allows addressing a diversity of objectives, at different temporal scales, by choosing the best MIT for those goals. As shown here and in several studies (Dunkerley, 2008b; Haile et al., 2011), the MIT chosen to define rainfall events has important consequences on the properties of the events. This indicates that, in research based on rain events, the choice of criterion to separate them can be crucial. Dunkerley (2008) shows how a change from a 24-hour MIT to a 1-hour MIT alters the mean event duration from 3.98 to 0.92 hours, among other characteristics 


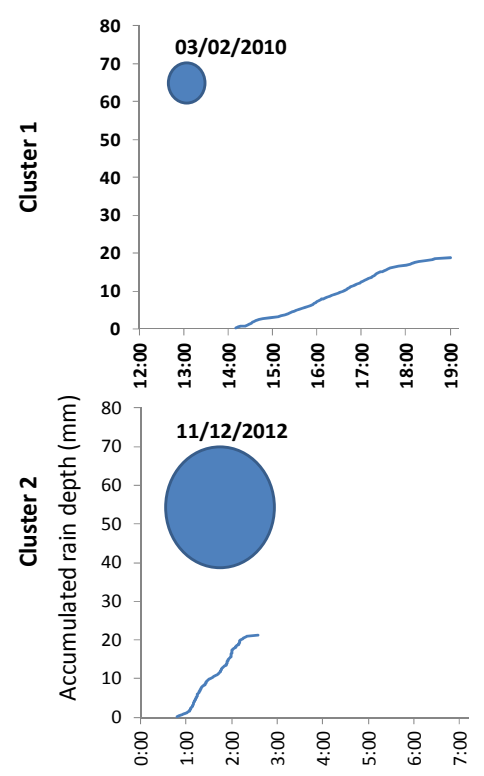

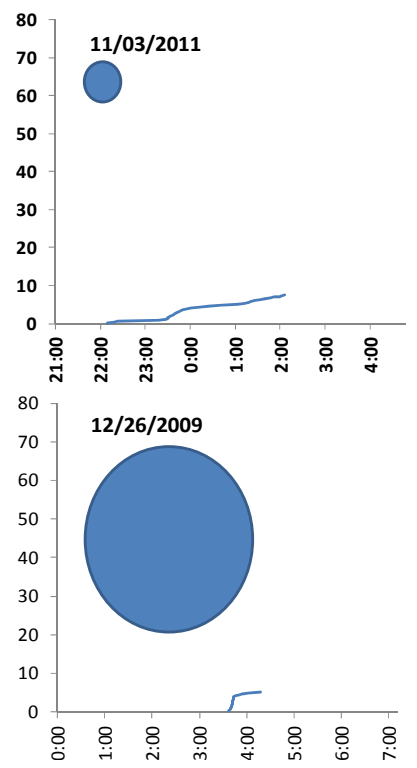

$01 / 26 / 201$

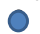

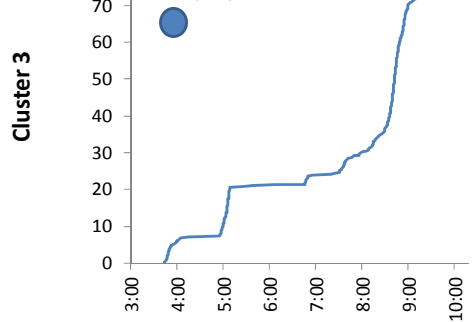

\begin{tabular}{c}
$70-$ \\
60 \\
50 \\
40 \\
30 \\
20 \\
10 \\
0 \\
\hdashline \\
\hdashline \\
$\stackrel{+}{+}$
\end{tabular}
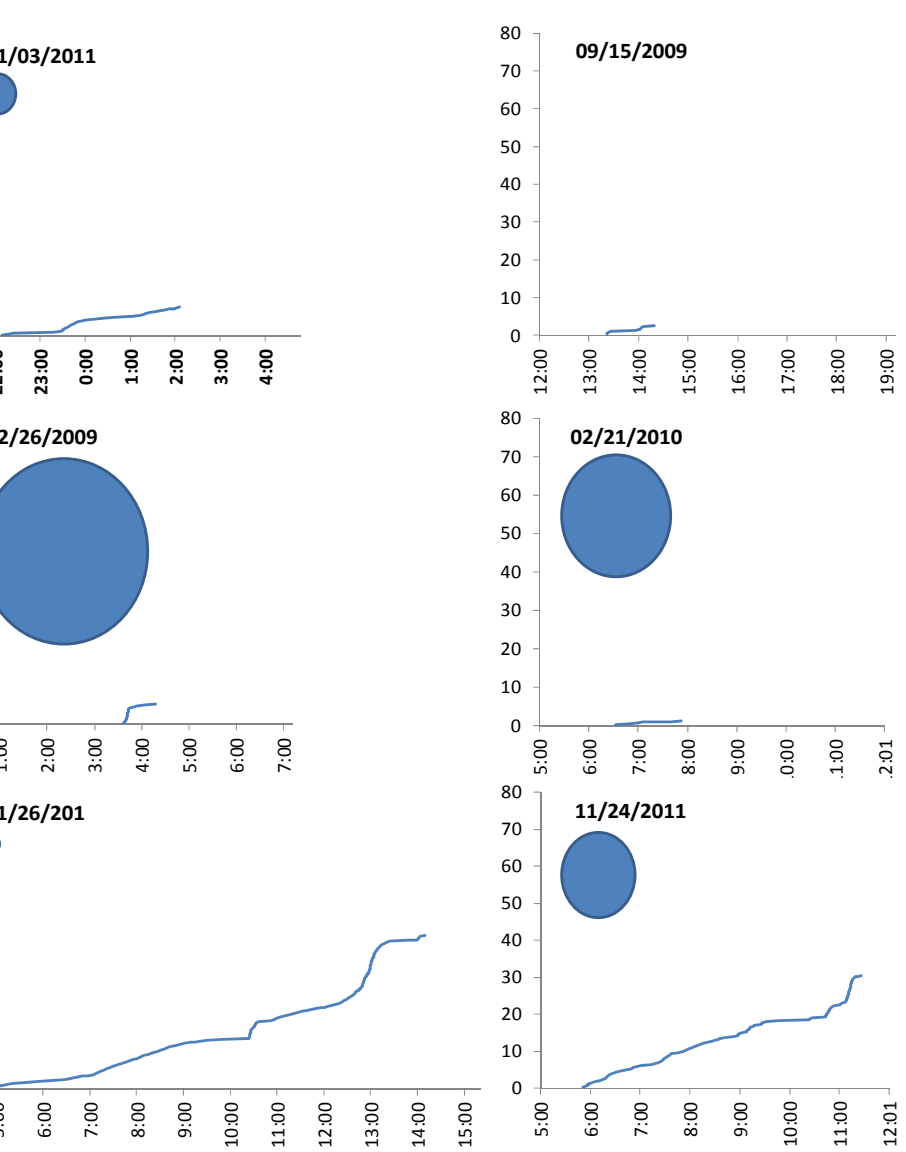

Time

Fig. 7. Cumulative rainfall graphs for three events within each group. The events are ordered from greater to smaller amounts of accumulated rainfall. The blue circles are proportional to the cumulative rainfall during the five days prior to the event.

Table 3. Result of the Kruskal-Wallis test showing that the difference in runoff among the rain groups was significant in each plot.

\begin{tabular}{rcc}
\hline Plot & $\begin{array}{c}\text { Kruskal-Wallis statistic } \\
\mathrm{H}(\mathrm{df} 2, N=46)\end{array}$ & $\mathrm{p}$ \\
\hline 1 & 9.602 & 0.0082 \\
2 & 15.645 & 0.0004 \\
3 & 10.388 & 0.0050 \\
4 & 19.048 & 0.0001 \\
5 & 22.101 & 0.0000 \\
6 & 9.598 & 0.0082 \\
7 & 13.998 & 0.0009 \\
8 & 29.418 & 0.0000 \\
9 & 13.319 & 0.0013 \\
10 & 16.279 & 0.0003 \\
11 & 12.564 & 0.0019 \\
12 & 8.188 & 0.0167 \\
13 & 18.702 & 0.0001 \\
14 & 13.318 & 0.0013 \\
15 & 16.764 & 0.0002 \\
16 & 19.664 & 0.0001 \\
\hline
\end{tabular}

of the events, in a dry area of Australia. In our case, the differences depending on the selected MIT were still larger. For example, the duration decreased, on average, from $15.90 \mathrm{~h}$ using a 24-hour MIT to $0.59 \mathrm{~h}$ for 1-hour MIT, and the mean rainfall depth decreased from $4.37 \mathrm{~mm}$ to $1.59 \mathrm{~mm}$, although the rain intensity changed little (Table 1).

Sometimes, the selection of the MIT seems somewhat arbitrary. Even in some cases in which an autocorrelation analysis is made, the time selected for the MIT does not refer to any level of significance in the autocorrelation. However, in other cases (for example, in Gaal et al., 2014), they used the lag in which the autocorrelation loses significance as the MIT. This is possibly one of the best ways to objectively select the best MIT for general purposes. Nevertheless, the autocorrelation may not be useful if the rainfall data series is too short. In the study of Gaal et al. (2014), based on a 32-year rainfall series, the autocorrelation lost its significance when reaching about a 2-hour lag, so they adopted a 2-hour MIT. In our case, the autocorrelation analysis was significant for lags shorter than 23 hours. This was possibly due to (i) the use of 5-minutes rainfall totals for the autocorrelation (to keep the high time resolution to use $T_{0}$ as a surrogate), because that detailed rainfall series includes a large amount of zeros, which were included because they are real rainfall values, not missing; and (ii) the limited length of our rainfall data series, because as the dates of the raindais differ considerably among years, the autocorrelation would decreases by lengthening the series. A 23-hour MIT seems too long for a study on the relationship between rain and runoff at a detailed scale. It implies that, within each event, there could be periods of almost 23 hours without rain, during which there may have been significant evaporation and deep infiltration. The resulting events are quite independent, but also quite complex. Due to this, we proposed here an alternative way of choosing the most suitable MIT, using multivariate regression with runoff.

The set of rain events established using a particular MIT might not be the most appropriate or have more explanatory power in studies of runoff, erosion or other processes (Dunkerley, 2008b; Restrepo-Posada and Eagleson, 1982). That is to say, the MIT must be chosen after taking the purpose of 
the research into account - which was one additional reason for the regression procedure followed here.

The MITs most commonly used in the literature are relatively short (usually between six and eight hours) (Dunkerley, 2008b). When choosing a large MIT, long periods without rain (even only slightly shorter than the MIT) can occur during the event. These periods allow water to evaporate from the canopy and, thus, tend to increase the rate of interception during the event. Additionally, allowing for partial deep infiltration of ground water, these periods make the soil stores available to be filled when rainfall resumes, which has an effect on runoff (Aryal et al., 2007; Dunkerley, 2008a). Therefore, the longer the MIT and the larger independence there is between events, the greater the independence between the parts of an event. According to Dunkerley (2015), the larger the rainfall duration and volume, the lower the intermittency fraction (the rate of non-rainfall time with regard to the total event time). However, the larger the MIT, the larger the intermittency fraction will be (Dunkerley, 2015), even when the most demanding criterion is used to define the non-rainfall time (rainfall $<0.1 \mathrm{~mm} / \mathrm{h}$ ). This means that choosing a large MIT produces more independent events but decreases their number and increases their duration and intra-event variability, as well as the complexity of their effects on runoff. There is evidence that the distribution of the rain intensity within an event can play a crucial effect on runoff (Dunkerley, 2012). Concretely, the runoff coefficient for given conditions increases according to the following sequence: constant intensity during the event, peak intensity early in the event and peak intensity at the end of the event (Dunkerley, 2012). When the study is focussed on a detailed time scale, a shorter MIT allows runoff to be related to rainfall periods equivalent to each part of a complex event resulting from a large MIT, facilitating an understanding of the runoff as a response by simplifying the hyetograph, if the antecedent conditions are considered. Besides, the shorter the MIT, the larger the amount of available data but also the greater the effect of the antecedent conditions on the runoff.

According to our results, the effect of varying the MIT from 30 minutes to 24 hours increased the average associated runoff by a factor of 3.24. Interestingly, although the absolute runoff volume strongly depended on the surface features, this increasing factor, as well as others factors relating any pair of MITs, were independent of the surface features and the variation of runoff with MIT always showed a very good fit to a positive potential curve. The limited length of our rainfall data series does not allowed the effect of the MIT on runoff to be compared with the effects of rain intensity or antecedent soil moisture. However, we found that the effect of MIT on runoff was in the range $(85-570 \%)$ of the effect on runoff of the rain intensity variations during the event, according to Dunkerley (2012).

According to our results, the optimal MIT to define rain events in order to better understand runoff at fine scale is one hour. From a physical viewpoint, after one hour without rain, the effect of the previous rain is still important. The evapotranspiration during that hour is quite low, ca. $0.18 \mathrm{~mm}$ (if water is not limiting), since total annual potential evapotranspiration in the area is about $1600 \mathrm{~mm}$ (Lázaro et al., 2004). However, the full decrease of the soil moisture reached between 5 and 10 percentage points, according to our own unpublished measurements, consistent with those of Canton et al. (2004) from a nearby site. Therefore, although the runoff was still quite dependent on the antecedent conditions, it was already mainly dependent on the on-going rainfall, as the highest determination coefficient of the 1-hour MIT showed. A decrease in soil moisture of 5-10 percentage points can represent the drainage of most of the water in the largest macropores, which could represent an important proportion of the whole soil porosity and have a significant effect on runoff. A small amount of continuous macroporosity can transmit a significant amount of water (Luxmoore et al., 1990). In this area, larger macropores are particularly concentrated under the dominant grasses (Mora and Lázaro, 2013, 2014), and their emptying would allow them to enhance their role as runoff sinks, making the events separated by 1-hour MIT relatively independent. The importance of the filling and emptying of the macropores was also highlighted by Calvo et al. (2003). Nevertheless, for the 30-minute MIT, the effect of the antecedent conditions can be dominant. Lázaro et al. (2015) demonstrated that, after 20 minutes without rain, the runoff produced by new rainfall is very significantly determined by the soil moisture produced by the former rain.

A consequence of choosing a 1-hour MIT was that only 13 events had a volume $>15 \mathrm{~mm}$ (Figure 5 ). Further, only $6 \%$ of these events generated runoff in some of the plots. There was no linear relationship between the intensity and duration of the events, but rain events with large volumes included usually most of the higher intensities.

The rain events produced by a 1-hour MIT were classified into three significantly different groups: large and intense rains, small and slightly intense rains that occurred on wet soil and small and slightly intense rains on dry soil. The first group produced most of the runoff; despite this, each group had significantly different volumes of produced runoff. Other authors classified the rain according to its hyetograph (see, for example, Coutinho et al., 2014), and some, such as Fang et al. (2012), classified events using K-means clustering, as in the present study. Fang et al. (2012) based their study on the volume, duration and $\mathrm{I}_{30}$ max rain variables, from which the runoff generation depends (Critchley and Klaus, 1991), and classified rains into three regimes: Regime I, or events of a medium amount and duration; regime II, or events with high water amounts, long duration and an infrequent occurrence; and regime III, or events with low water amounts, short duration and high frequency. They concluded that, although regime II causes high runoff coefficients, as these events are infrequent, the intermediate events cause the greatest total accumulated discharge. In our case, besides the rain variables used by Fang et al. (2012), we added to the cluster analysis the accumulated rain on the previous day, which is also an important factor affecting runoff (Kampf, 2011). The small events were dependent on the antecedent conditions and this separation was confirmed by different runoff production. However, for the larger events, the antecedent conditions were not as relevant.

In our study area, winter rain events were longer and summer/fall events were more intense. The largest periods between consecutive rains always occurred in the summer, which is consistent with the well-studied longer rainfall series in a nearby area (Lázaro et al., 2001, 2004). It is worth noting the large number of single-tip events. Many of these isolated tips could be due to dew, which is very common in the area, even in the dry months of summer, and is capable of producing pulses in the rain gauge according our observations. Of the rain events, $63.75 \%$ were single-tip events, although they represented only $9.57 \%$ of the total $\mathrm{mm}$ collected throughout the study period. This is consistent with the results of Uclés et al. (2013) in the same area of study, who showed that dew condensation occurred on $78 \%$ of the nights and that annual dew represented 9$23 \%$ of total registered water input in $\mathrm{mm}$. This dew has a very important role in a semiarid ecosystem, as it is a constant source of water. 
Acknowledgements. This study was supported by the PREVEA research project (CGL2007-63258/BOS) funded by the Spanish Ministry of Science and Innovation and the European Regional Development Fund; by the Mesotopos (Excellence Project P08RNM-04023, funded by the Junta de Andalucia (Autonomous Government of Andalusia, Spain); and by the SCIN (Soil Crust Inter-National, PRI-PIMBDV-2011-0874, European project of ERA-NET BIODIVERSA), the Spanish team being funded by the Spanish Ministry of Economy and Competitiveness). I. Molina-Sanchis was supported by a FPU research grant funded by the Spanish Ministry of Science and Innovation. We thank also the authority of the Cabo de Gata-Nijar Natural Park to allow installing the experiment at the Balsa Blanca site. We are very grateful to David Dunkerley and Peter Molnar for their very constructive and useful comments to an early version of the manuscript.

\section{REFERENCES}

Abdo, K.S., Fiseha, B.M., Rientjes, T.H.M., Gieske, A.S.M., Haile, A.T., 2009. Assessment of climate change impacts on the hydrology of Gilgel Abay catchment in Lake Tana basin, Ethiopia. Hydrol. Process., 23, 3661-3669.

Aguiar, M.R., Sala, O.E., 1999. Patch structure, dynamics and implications for the functioning of arid ecosystems. Trends Ecol. Evol., 14, 273-277.

Angel, J.R., Palecki, M.A., Hollinger, S.E., 2005. Storm precipitation in the United States. Part II: Soil erosion characteristics. J. Appl. Meteorol., 44, 947-959.

Aryal, R.K., Furumai, H., Nakajima, F., Jinadasa, H.K.P.K., 2007. The role of inter-event time definition and recovery of initial/depression loss for the accuracy in quantitative simulations of highway runoff. Urban Water Journal, 4, 53-58.

Asquith, W.H., Roussel, M.C., Thompson, D.B., Cleveland, T.G., Fang, X., 2005. Summary of dimensionless Texas hyetographs and distribution of storm depth developed for Texas Department of Transportation. Research Project 04914. Austin, Texas: U.S. Geological Survey, Report 04194-4.

Balme, M., Vischel, T., Lebel, T., Peugeot, C., Galle, S., 2006. Assessing the water balance in the Sahel: Impact of small scale rainfall variability on runoff. Part 1: Rainfall variability analysis. J. Hydrol., 331, 336-348.

Bonta, J.V., Rao, A.R., 1988. Factor affecting the identification of independent storm events. J. Hydrol., 98, 275-293.

Bracken, L.J., Cox, N.J., Shannon, J., 2008. The relationship between rainfall inputs and flood generation in south-east Spain. Hydrol. Process., 22, 683-696.

Brown, B.G., Katz, R.W., Murphy, A.H., 1985. Exploratory analysis of precipitation events with implications for stochastic modelling. J. Appl. Meteorol. Clim., 24, 57-67.

Calvo-Cases, A., Boix-Fayos, C., Imeson, A.C., 2003. Runoff generation, sediment movement and soil water behaviour on calcareous (limestone) slopes of some Mediterranean environments in southeast Spain. Geomorphology, 50, 269-291.

Cantón, Y., Solé-Benet, A., Domingo, F., 2004. Temporal and spatial patterns of soil moisture in semiarid badlands of SE Spain. J. Hydrol., 285, 199-214.

Cattan, P., Cabidoche, Y.M., Lcas, J.G., Colz, M., 2006. Effects of tillage and mulching on runoff under banana (Musa spp.) on a tropical Andosol. Soil Till. Res., 86, 38-51.

Critchley, W., Siegert, K., 1991. A manual for the design and construction of water harvesting schemes for plant production. FAO, Rome.
Coutinho, J.V., Das, N., Almeida, C.M.F., Leal, A., Barbosa, L.R., 2014. Characterization of sub-daily rainfall properties in three raingauges located in northeast Brazil. In: Proc. ICWRS2014 Evolving water resources systems: understanding, predicting and managing water-society interactions, IAHS Publ. 364, Bologna, Italy. doi: 10.5194/piahs-364345-2014

de Vos, N.J., Rientjes, T.H.M., 2008. Multiobjective training of artificial neural networks for rainfall - Runoff modeling. Water Resour. Res., 44: W08434.

Dunkerley, D., 2008a. Rain event properties in nature and in rainfall simulation experiments: A comparative review with recommendations for increasingly systematic study and reporting. Hydrol. Process., 22, 4415-4435.

Dunkerley, D., 2008b. Identifying individual rain events from pluviograph records: A review with analysis of data from an Australian dryland site. Hydrol. Process., 22, 5024-5063.

Dunkerley, D., 2010. How do the rain rates of sub-event intervals such as the maximum 5- and 15-minute rates $\left(\mathrm{I}_{5}\right.$ or $\left.\mathrm{I}_{30}\right)$ relate to the properties of the enclosing rainfall event? Hydrol. Process., 24, 2425-2439.

Dunkerley, D., 2012. Effects of rainfall intensity fluctuations on infiltration and runoff: rainfall simulation on dryland soils, Fowlers Gap, Australia. Hydrol. Process., 26, 2211-2224.

Dunkerley, D., 2015. Intra-event intermittency of rainfall: an analysis of the metrics of rain and no-rain periods. Hydrol. Process., 29, 3294-3305.

Fang, N.F., Shi, Z.H., Li, L., Guo, Z.L., Liu, Q.J., Ai, L., 2012. The effects of rainfall regimes and land use changes on runoff and soil loss in a small mountainous watershed. Catena, 99, 1-8.

Fornis, R.L., Vermeulen, H.R., Niewenhuis, J.D., 2005. Kinetic energy-rainfall intensity relationship for central Cebu, Philippines for soil erosion studies. J. Hydrol., 300, 20-32.

Gaál, L., Molnar, P., Szolgay, J., 2014. Selection of intense rainfall events based on intensity thresholds and lightning data in Switzerland. Hydrol. Earth Syst. Sci., 18, 15611573.

Grace, R.A., Eagleson, P.S., 1967. Scale model of urban runoff from storm rainfall. J. Hydraulics Division, 93, 161-176.

Haile, A.T., Rientjes, T.H.M., Habib, E., Jetten, V.G., Gebremichael, M., 2011. Rain event properties at the source of the Blue Nile River. Hydrol. Earth Syst. Sci., 15, 1023-1034.

Hawke, R.M., Price, A.G., Bryan, R.B., 2006. The effect of initial soil water content and rainfall intensity on nearsurface soil hydrologic conductivity: A laboratory investigation. Catena, 65, 237-346.

Heydarpour, J., 1989. Modeling runoff in semiarid rangeland watersheds. Environ. Softw., 4, 210-215.

Huxman, T.E., Snyder, K.A., Tissue, D., Leffler, A.J., Ogle, K., Pockman, W.T., Sandquist, D.R., Potts, D.L., Schwinning, S., 2004. Precipitation pulses and carbon fluxes in semiarid and arid ecosystems. Oecologia, 144, 254-268.

Ignaccolo, M., De Michele, C., 2010. Statistical collapse of stratiform and convective drop diameter distributions at the ground. Geophys. Res. Lett., 37, L24402 doi: 10.1029/2010GL045454

Lázaro, R., 2004. Implications of precipitation on vegetation of water-limited lands. In: Pandalai, S.G. (Ed.): Recent research development in environmental biology, 1. Research Signpost, Kerala (India), pp. 553-591.

Lázaro, R., Rodrigo, F.S., Gutiérrez, L., Domingo, F., Puigdefábregas, J., 2001. Analysis of a 30-year rainfall record (1967-1997) in semiarid SE Spain for implications on vegetation. J. Arid Environ., 48, 373-395. 
Lázaro, R., Rodríguez-Tamayo, M.L., Ordiales, R., Puigdefábregas, J., 2004. El Clima. In: Mota, J., Cabello, J., Cerrillo, M.I., Rodríguez-Tamayo, M.L. (Eds.): Subdesiertos de Almería: naturaleza de cine. [Sub-deserts of Almeria: landscapes of cinema]. Consejería de Medio Ambiente, Junta de Andalucía, Almería, Spain, pp. 63-79. (In Spanish.)

Lázaro, R., Calvo-Cases, A., Lázaro, A., Molina, I., 2015. Effective runoff flow length over biological soil crusts on silty loam soils in drylands. Hydrol. Process., 29, 25342544.

Lloyd, C.R., 1990. The temporal distribution of Amazonian rainfall and its implications for forest interception. Q. J. Roy. Meteor. Soc., 116, 1487-1494.

Luxmoore, R.J., Jardine, P.M., Wilson, G.V., Jones, J.R., Zelazny, L.W., 1990. Physical and chemical controls of preferred path flow through a forested hillslope. Geoderma, 46, $139-154$.

Mayor, A.G., Bautista, S., Bellot, J., 2011. Scale-dependent variation in runoff and sediment yield in a semiarid Mediterranean catchment. J. Hydrol., 397, 128-135.

Mora, J.L., Lázaro, R., 2013. Evidence of a threshold in soil erodibility generating differences in vegetation development and resilience between two semiarid grasslands. J. Arid Environ., 89, 57-66.

Mora, J.L., Lázaro, R., 2014. Seasonal changes in bulk density under semiarid patchy vegetation: the soil beats. Geoderma, 335-336, 30-38.

Peters, O., Christensen, K., 2002. Rain: Relaxations in the sky. Phys. Rev., 66, 036120.

Peters, O., Christensen, K., 2006. Rain viewed as relaxational events. J. Hydrol., 328: 46-55.

Peters, O., Hertlein, C., Christensen, K., 2001. Complexity View of Rainfall. Phys. Rev. Lett., 88, 018701

Porporato, A., D’Odorico, P., Laio, F., Ridolfi, L., RodríguezIturbe, I., 2002. Ecohydrology of water controled ecosystems. Adv.Water Resour., 25, 1335-1348.

Puigdefábregas, J., Solé, A., Gutierrez, L., Del Barrio, G., Boer, M., 1999. Scales and processes of water and sediment redistribution in drylands: Results from the Rambla Honda field site in Southeast Spain. Earth-Sci. Rev., 48, 39-70.

Puigdefábregas, J., 2005. The role of vegetation patterns in structuring runoff and sediment fluxes in drylands. Earth Surf. Proc. Land., 30, 133-147.
Restrepo-Posada, P.J., Eagleson, P.S., 1982. Identification of independent rainstorms. J. Hydrol., 55, 303-319.

Rey, A., Pegoraro, E., Oyonarte, C., Were, A., Escribano, P., Raimundo, J., 2011. Impact of land degradation on soil respiration in a steppe (Stipa tenacissima L.) semiarid ecosystem in the SE of Spain. Soil Biol. Biochem., 43, 393-403.

Sánchez, G., Puigdefábregas, J., 1994. Interactions between plant growth and sediment movement in semiarid slopes. Geomorphology, 2, 43-60.

Struthers, I., Sivapalan, M., Hinz, C., 2007. Conceptual examination of climate-soil controls upon rainfall partitioning in an open-fractured soil: 1 . Single storm response. Adv.Water Resour., 30, 505-517.

Uclés, O., Villagarcía, L., Moro, M.J., Canton, Y., Domingo, F., 2013. Role of dewfall in the water balance of a semiarid coastal steppe ecosystem. Hydrol. Process., 28, 2271-2280.

Usón, A., Ramos, M.C., 2001. An improved rainfall erosivity index obtained from experimental interrill soil losses in soils with a Mediterranean climate. Catena, 43, 293-305.

Wenzel, H.G., Voorhees, M.L., 1981. An evaluation of the urban design storm concept. University of Illinois, Water Resources Center, Urbana-Champaign, Illinois, USA.

Wischmeier, W.H., Smith ,D.D. ,1978. Predicting rainfall erosion losses-A guide to conservation planning. U.S. Department of Agriculture, Agriculture Handbook 537. Hyattsville, Maryland.

Woolhiser, D.A., Osborn, H.B., 1985. A stochastic model of dimensionless thunderstorm rainfall. Water Resour. Res., 21, 511-522.

Zeng, N., Shuttleworth, J.W., Gash, J.H.C., 2000. Influence of temporal variability of rainfall on interception loss. Part I. Point analysis. J. Hydrol., 228, 228-241.

Zhang, G.P., Fenicia, F., Rientjes, T.H.M., Reggiani, P., Savenije, H.H.G., 2005. Modeling runoff generation in the Geer river basin with improved model parameterization to the REW approach. Phys. Chem. Earth, 30, 285-296.

Ziegler, A.D., Negishi, J.N., Sidle, R.C., Noguchi, S., Nik, A.R., 2006. Impacts of logging disturbance on hillslope saturated hydraulic conductivity in a tropical forest in Peninsular Malaysia. Catena, 67, 89-104.

Received 23 March 2015 Accepted 14 April 2016

Note: Colour version of Figures can be found in the web version of this article. 